\title{
Prose miniatures as an experience of self- identification (author's mini-texts in the Vepsian language)
}

\author{
Galina Ivanova, ${ }^{1, *}$ \\ ${ }^{1}$ Novosibirsk State University of Architecture and Civil Engineering (Sibstrin), 113, Leningradskaya \\ str., Novosibirsk, 630008, Russia
}

\begin{abstract}
Prose miniatures of Alexander Ulyanov are analyzed not only as a way of self-expression of the author's ego, but also as an experience of self-identification, awareness of their place in the social world order and historical time. The format of the miniature cycle appears as a convenient form of reproducing key moments of a person's life, which corresponds to the mechanism of memories as processing pop-up engrams of episodic memory into a complete self-reflection. At the same time, focusing on a particular idea unfolds in a specific situation in life. The creative principle of the author of miniatures serves the pragmatics of social adaptation in the surrounding stressful world. It is creativity that turns out to be a tool for assembling the personality in its multiple forms and serves as a way of integration into a heterogeneous external environment. The mechanisms of constructing miniatures in the perspective of achieving self-reliance and integration into the surrounding world are considered. Namely, the thematic diversity, the author's initial data representing a «fluid identity» typical for a person of the twentieth century with the help of a cumulative attitude to «collecting stones» are successfully overcome in the choice of a reflective style of description and the absence of hasty subjective conclusions. The core of self-identification of the series of miniatures by A. S. Ulyanov translates to the reader dignity, self-confidence and readiness for any tests.
\end{abstract}

\section{Introduction}

The author of the miniatures, which will be discussed in the article, is unknown to the reader. During my work on my dissertation on the Vepsian language [1], A. S. Ulyanov gave me the mintexts as samples of Vepsian speaking. After reading them, it became obvious that they are worthy of the attention of a wider range of readers, moreover, they could be used as educational texts in the study of the endangered Vepsian language [2].

Alexander Sergeevich Ulyanov (20.08.1933 - 21.11. 2018) was born in the village of Mardai in the Alarsky district of the Irkutsk region in a Veps family [3]. He graduated From the Higher-Usovskaya secondary school, worked at a factory, in the police, as a

* Corresponding author: tervhen66@mail.ru 
correspondent in the regional newspaper «East Siberian truth»-changed more than one profession. He was a winner of the first all-Union exhibition of artists and journalists in Moscow, a participant of many festivals. Alexander Sergeevich is not only a master of graphics and painting, but also of works of literary creativity, which will be discussed in this article.

A. S. Ulyanov's prose can be defined as «miniatures» - autobiographical stories about people the author met and about events in which he was a participant, with a volume of one paragraph (approximately ten lines).

\subsection{The research goal}

Consider prosaic miniatures not only as a form of self-expression available to everyone, but also as a way of self-identification in the perspective of creating a «portrait of time». Determine the stylistic originality of A. S. Ulyanov's miniatures and describe the methods of their construction.

\section{Materials and methods}

Form and genre. Miniatures are an ancient form of expression of artistic images. The history of creating miniatures goes back millennia. Since people first began to develop art, they have been making objects in miniature. Miniaturization is often characterized as a process in which an entity, a thing, moves from large to small $[4,5]$. However, there is another point of view on this process: miniaturization does not begin on a large scale, it begins with a huge and significant - ideas and ideologies. For the Makah of chapter four, a miniature canoe does not begin with a large canoe, but with almost inconceivably complex, social, technological and demographic movements during the process of colonisation. For the Ancient Egyptian craftsmen of chapter three, their miniatures start not with livestock, or pottery, or boats, but with everyday intra- or inter-communal transactions and a diverse array of rituals [6].

For most of history, it has been almost impossible to effectively convey broad-scale movements to a specific audience through traditional speech or writing, which is too dense and cumbersome. A vector was needed by which these complex ideas could be reduced and simplified. This vector was miniaturization.

«It is this whole sequence, from conception, to selection, to construction, to distribution to intended audiences, that forms the miniaturisation process» [6].

«We do not claim that miniatures are created for a single purpose. Unlike a more prosaic, mechanical tool, miniatures by nature of their imaginative dimensions are multifaceted pieces of equipment for coping with and changing the world. They are consequently readily adaptable to different or changing circumstances, and engaged in such diverse human practices as education, commerce, worship and experimentation through the powerful engine of human imagination, which can associate alternate realities to physical objects» [6]. « ... demonstrates the ways in which miniatures speak about and are connected to much broader and more complex movements and phenomena, and are enabled to do so with particular efficacy due to their imaginative and dissonant engagement with scale, mimesis and simplicity» [6].

In literature a miniature is a prose work less than a story, «usually containing a thought (image) of a broad generalization or vivid character»; its compositional and meaningful completeness distinguishes it from the fragment [7].

Some consider the miniature a prose poem, while others consider it a short story. The founder of the literary and artistic genre of miniatures is considered to be I. S. Turgenev with his «Poems in prose». «Poems in prose» were also written by V. Garshin and I. 
Annensky. Short, miniature stories were given great importance by I. Bunin, V. Korolenko, and A. Kuprin. The literature of the second half of the twentieth century is also marked by the appearance of a large number of mintexts: lyrical miniatures are collected by $\mathrm{Y}$. Bondarev («Moments»), A. Solzhenitsyn («tiny»), V. Astafiev («Zatesi»), V. Shukshin. The study of mini-genres in Russian literary studies is carried out by Orlitsky Yu. B., Leiderman N. L., Smirnov I. P., and others $[8,9,10]$. At the moment, there is no single genre classification of miniatures. Despite this, the literature clearly identifies typologically similar works, the analysis of which allows us to speak about the presence of specific varieties of the genre: miniatures-descriptions, miniatures-arguments, miniatures-memories, household sketches («genre scenes»), parables, mini-tales.

All these types of thumbnails have common features that can be combined into a single class: brevity and super-brevity of volume, one-eventedness, cyclization, and an element of philosophy.

2. Philosophical basis The tendency to minimize literary genres reflects General global processes: Informatization, accelerated rhythm (dynamism) of life, variability, fluidity, fragmentarity. A person faces challenges how to adequately reflect this new external world, other objects in it, and most importantly - how to position yourself in this world, your own «I». The attitude to oneself is especially important for achieving personal identity in the flow of life, finding a place in it, reading yourself into the kaleidoscopic world. «In identities, as in a mirror, our complex world is reflected, based on differences and constantly in search of a model for overcoming them, sometimes not noticing similarities and identities as the basis for interaction» [11].

The question «Who am I?» is not only a subject of philosophical reflection, but also an expression of everyday challenges experienced by many people. At the end of the XX century, the problem of self-consciousness, self-determination as a person in the circle of others is one of the main problems of philosophical thought and modern society as a whole. Therefore, there are reasons to apply the terms of philosophical science in a more extended understanding. «Philosophy of life in the broad sense of the word is any philosophy that raises questions about the meaning, purpose, and value of life» [12].

3. The problem of identity Complex human activity for self-determination, the result of which is the true identity of a person with himself, is considered self-identification. Identification as such is «a conscious or unconscious action in which someone (an individual, group, or society) makes the statement «I (We) are that». In the process of identification, the content, structure, concept and meaning of «that» with which one identifies oneself is affirmed, and through this action, that which identifies itself with something describes its own content, structure, concept and meaning. Identity is a property of human consciousness» [13].

Self-identification - subject-subject relationship, the process of relating oneself to oneself, as a result of which the idea of oneself as an identical, integral and unique person is formed. The need for self-determination (establishing certain limits of the «I» and, at the same time, the need to transcend these boundaries), self-identity has always been an important human need. Erich Fromm wrote: «The need for identity is so vital and imperious that a person cannot feel healthy if he does not find a way to satisfy it. The need for emotional self-identification is rooted in human nature, comes from the very conditions of human existence and serves as the source of our intense aspirations» [14].

Our research methods are based on historical-cultural, socio-psychological, mythopoetic and transcultural approaches. When working with the texts of the miniatures we used a method of continuous sampling. 


\section{Discussion}

\subsection{Originality of Alexander Ulyanov's miniatures}

The genre of miniatures is very convenient for assembling itself into a whole: it corresponds to the author's request to search for and understand the personality, the need to identify oneself - on the one hand, on the other - to fit into the «collective portrait», to see one's place in the row of other people and events - to try to identify oneself with others. The dispersion and atomization of the unique personality qualities of modern life in the format of a miniature starts the reverse process - the folding of personality puzzles for its positive existence. In this case, the miniature appears as a model of fixing the life path at the time of its creation, the mnemonic process is embodied in the product of creativity.

The purpose of A. S. Ulyanov's miniatures, as we think, is to describe the sociopsychological experience of becoming a person for self-identification and integration into the «collective common». Offer an experience of understanding your own life to determine its value.

The cycle of miniatures by A. S. Ulyanov is a series of autobiographical memoirs that collect, generalize the author's life experience and form his image. The «I» is «reflexively understood by the individual in ... his biography» [15]. «Autobiography is the core of selfidentity in modern social life» [15].

Each miniature is dedicated to a key life episode that helps the author reflexive their Self on different levels and in different identities:

- origin (roots), relocation of parents,

- place of birth and childhood,

- nationality,

- involvement in the Motherland, history, and society,

- connection and communication with nature,

- attitude to religion.

The cycle opens with miniatures of the parents moving from the village of Pondala in Vologda province - the original place of residence of the Veps - to Siberia:

Minun Tatko Mamkume Sibirihe ez'mäižen kerdan tuudihe 1910 vodou ühtes heimolaižime. 'My father and mother came to Siberia for the first time in 1910 together with relatives'.

Siberia seemed to be a free land, and my parents wanted to find a happy life there, but they were disappointed «sigau hüvä ma oli gö antut i tatkolo putui siä pedaimecame. Kaiken tauhen hö ratihe nečüu siäu, a kevadou tehtihe pažagad i puutihe oksad da kandod. Kuume vot mokičihezoi kazvataäd, a viilad kazvatada ii vügoi. ... i hö mamkome pörttihe Pondlalo» 'the good land there was already occupied, and my father got two tithes in the pine forest. Throughout the winter, the settlers cleared the land, and in the spring, they burned what was not going into construction. For three years my parents suffered with this land, but no matter how hard they tried, they did not grow bread on it... and returned to Pondala'. The first unsuccessful experience of relocation of parents to Siberia did not affect, however, after some time to decide on the second, which turned out to be happy. Referring to this period of family history helps the author to assert the human right to choice and will: «And again my father decided to try his luck».

Origin is an important position for a person's self-identification: Where are my roots? What family am I from? The author of the origin of Veps by birth - Siberian, for civic identity - the Soviet people Who is he? A. Ulyanov thinks about this confidently, without focusing on any one quality, he tries to firmly link these differences and embed, integrate himself into the «collective common», fit into the General context of time. The family is 
reported sparingly, but with dignity and respect: for example, the full names of parents are given:

Minun sizared i vell' tuudihe tanna Vologodskiän guberniäspäi, a mina sündnu tägau Sibiriš vepsan kanzas Ul'anova Sergeä Andreeviča i Marii Sergeevny. 'All my sisters and brother came from Vologda province, and I was born here in Siberia, in the family of Veps Ulyanov Sergey Andreevich and Maria Sergeevna'.

About half of the cycle's miniatures are a measured panorama of childhood. Against this background, the «Anomaly» looks especially bright and symbolic» - meeting with an inexplicable, mysterious phenomenon:

Konz tuli aig longiitada, kacum ülähämpäi irdame astub pahoin' sur' akk, mugoitte sur, miše kaks' minun mamkod tari. Sädo hänou pit'k must, jäugad kengata i kaglan päi ripub rusked kadipaik. Hibusod pit'kad i passtut. Ukod i akad, ken olibad irdau, ristatid'he ocad i uittihe ičezoi tanhalo. Mina vähäižen jöksin'prihäižid'me akan taga i nägin'kut hän kumarzihe verain'au miše ii iškta päd. Verain' taga neco akk kadoi miiden süumišpäi kuti sau. Konz mö openzimoiš vanhas školas, ka küzuim opendail’: mi neco oli? Opendaäd sanutihe: «Anomaliä».

'Before dinner, we watch a huge woman walking down the street, probably twice as tall as my mother. She is wearing black clothes, barefoot, a bright red long scarf hanging from her neck, and her hair is black and loose, like a madwoman's. Those who were on the street at this time, old women and women, somehow hurriedly crossed themselves and ran to their courtyard. I ran a little way after her with the other kids, and I saw this woman stoop to avoid hitting her head on the crossbar as she passed the gate. Outside the gate, it suddenly seemed to disappear. And when we were in high school, we asked our teachers: what was it and what did it mean? The answer was brief: «Anomaly»'.

«The frankly wonderful (terrible, inexplicable, alien) experiences feelings and forces them to recognize the existence of the unreal, to submit to the power of the impossible» [16].

The «anomaly» image is one of the key images in the thumbnail cycle. «Anomaly» can be seen as a hidden mysterious, mysterious constant of the world, a designation of an unconscious alternative, the possibility of another state of things, wrongness, failure, sudden intervention that is beyond the obvious coding. At the same time it is a necessary element of development - a tool for distinguishing between standard and violation, norms and deviations, as well as modality of the way of life. The latter interpretation creates a multidimensionality in the author's reflection on external events, his contemplation and postponement of conclusions. Perhaps this is due to the ethnic code - vepsi, unlike the communal Russians, lived on farms among swamps and forests, they are distinguished by their isolation, a tacit alertness to the strange, incomprehensible. Only the necessity of life prompted the ancestors of A. S. Ulyanov to overcome the age-old distrust and move from their homes, change their place of residence.

The theme of the connection between small and large, the involvement of a person in events of historical scale is actualized in the episode-the memory of an airplane burning in the sky over a remote Siberian village:

En mušta miččeu urokau kulom edahan komedan. Mö em dročetut siil' vozil' mašinoil,'ka sentäht jöksom ühtes opendaäme üknan noks i nägem kut lendab samolöt, a hänospäi vedaso must sau. Üht' nägoi hän palaškanz' lämoil' i lanktoškanz' alahaks. Mö pakičem opendaäd pässta miid' sinna, kuna lanktob samolöt. Opendai päst' i mö göksom mägišpai mägelo, a samolötad iile. Kuumandou päivau tundištim miše hän langez' sires deröunän Badonki. Nezo vižtošt'küme virstad miäupäi. Nügüt'so mö tedam miše letihe samolötad Americaspäi miihe i ii kaik puttihe siähä sai.

'I don't remember what lesson, we hear the distant hum of an airplane. We, not spoiled by cars in those years, rushed to the window with the teacher and see: a large plane is 
flying, followed by a plume of black smoke. Suddenly a fire appeared before our eyes and the plane began to fall. We ask the teacher to let us go, and run from mountain to mountain, and he is still not there. Three days later we learn that the plane crashed near the village Badonky is fifteen miles from us. Now we know that these planes were transported by our pilots from America through Alaska to the Soviet Union. Not all flew to the place, burned and fell, which we observed that day'.

Residents of a small village located six thousand kilometers from the fighting during the great Patriotic war, become witnesses of epoch-making terrible events. The plane for them is a big world, a reminder of the war that is burning now somewhere very far away, and the experience of their involvement in wartime. For the author, this memory serves as an awareness of the connection between phenomena that seem to be separated in space and time, but are actually integral parts of a single whole.

So, the features of the author's self-identification in A. S. Ulyanov's miniatures can be called:

1. Transitivity. Self-awareness of the author's personality is expressed by the sequence of transition from «I» to «we» («I» as part of a group of children to the community «Veps family», «I» and «residents of the Siberian village»), from the old to the new («small homeland» of parents as the historical homeland of the author changes to a new homeland relative to the author, his «small homeland» is already Siberia), from ignorance to knowledge (trip to Siberia).

2. Cumulative personality development, which is manifested in the accumulation of growth of qualities, knowledge, skills that lead to qualitative changes in its development, adding opportunities to understand yourself. The story of the parents ' move appears as an experience that has a direct, blood relationship to the author. It involves all participants of the event in the General flow of time: both the narrator and the reader. Despite the primary form of narration, the story is perceived in its objectively factual form.

3. Positive perception of the world around you, focusing on the positive aspects of events, self-confidence, pride in yourself and others. The author is not only a chronicler, but also a commentator who accepts the world as it is realized in reality. The picture of migration allusively refers to the «great migration of peoples» and in a narrower circle of symbolization embodies a positive transnational image of Russia as an expanding state developing its virgin lands.

4. Concise miniaturization in the selection of events (vital for the family and the family) becomes a launching pad for a wide field of associations and symbolic generalizations. The author's personal world appears as a microcosm in the spheres (stratosphere) of the macrocosm - race, ethnicity, country, historical cross-section, paranormal, etc.

\subsection{The structure of the thumbnail}

It is known from psychology that memory snatches the essence of an event from the past «engrams of episodic memory» [17], which are revealed from a new angle, corrected by time.

The process of remembering occurs according to a certain pattern: starting point deployment - ending.

The structure of miniatures-memories is built in accordance with this scheme:

a) a certain fragment of the author's life that is significant for self-identification is updated. The thesis is formulated as a starting point that serves as a tie. This can be a stable expression, a catch phrase, clinging to which the author begins to decipher it - and develops the plot;

b) «deployment» of the thesis and build-up of details; 
c) concentration of the plot on the denouement, the final chord, which acts as a kind of final formula (words, slogans, short sentences).

Here is an example from the birth thumbnail.

The beginning is a well-known phrase «Siä sündunoid' i kazvatoid' ii valita». 'Place of birth and parents are not chosen'.

This phrase can be applied to various situations: both positive and negative. The author deliberately takes a universally valid universal thesis to fill it with its own content, a personal happy story, to experience and actualize it for himself. The author strands the details, gives the details of his birth: ezmäine minun kabaloid oli kagranolg, a sündumabai räustaz, miččen tegi tat lehmalo i ol'gäd toi püudospäi... 'my first diaper was soft oat straw, and my maternity home was a barn that my father had built for the cow and even brought a bundle of straw for her from the field'..., which implicitly contain an allusion to the Evangelical birth of Jesus. The allusion is more Anthroposophical than religious and emphasizes the author's desire for maximum generalization - the horizons of the macrocosm. Childhood as a mythical Golden age, where man is in harmony with nature.

The ending defines the proposed thesis about the place of birth and parents: «Päiv oli läm, louvaz, päipaštokaz kaks'kümnen avgusta üks tuha kahccan sadad kuumeküme vot». 'It was a warm, Sunny, clear day on August 20, 1933' - this is a bright, warm start to a happy life.

The «neoliterates» presentation gives the impression of domestic correspondence, the effect of the «human document». This natural simplicity was sought by the Russian classics, starting with Alexander Pushkin, and Alexander Ulyanov, processing their own biographical material, clearly follows the classical models.

\subsection{Summarizing the facts}

The author of miniatures in a compressed form drew a portrait of time and society. As noted by Ivanov E. E. about avtobiograficheskoi prose G. Gazdanova: «The author's position contains a substrate, which in the course of narration accumulates a certain value system. This system is not mechanically expressed, but it vibrates in the obviousness of the situations the protagonist-observer is picking out from his memories» [18]. Artistry in A. S. Ulyanov's miniatures is achieved by careful selection of stylistic and linguistic means, General cultural subtext, consistent use of compositional techniques that allow us to speak about the poetics of these works. At the same time, the author's intention was expressed in a positive life-affirming aspiration. All means of expression are neutral: there are no special rhetorical figures, specific colorfulness (folk, ethnic or literary elements of style). A. S. Ulyanov's miniatures describe events that are important for any person: the origins, childhood, a sense of belonging to their history, to a large planetary world (miniature «Airplane») and a premonition of a potential threat to the visible peace, a sense of illusory present stability, which are presented in the «Anomaly».

The miniature cycle is an experience of self-identification, in which the author tries to understand and see himself in the context of time and in the ontological dimension. Analysis of the poetics of prose miniatures-memories of A. Ulyanov allows us to conclude:

1. They have both universal properties (small volume, information saturation, artistic completeness, integrity) and specific ones: awareness of historical time from the position of an artist - observer.

2. The Author seeks to overcome the chaotic, turbulence of the objective world by creative self-identification, the expression of which is the cycle of miniatures.

3. The image of the author in miniatures appears as a person who overcomes the entropy of momentary time and organically fits into any possible scale: biographical, mental, social, cultural and metaphysical. 


\section{Conclusion}

In the future, the work can be continued at the level of language analysis of A. S. Ulyanov's miniatures and the study of means of expressing the author's self-identification. It seems appropriate to consider the form-content and language gaps of the bilingual discrepancy between the Russian and Vepsian versions of the miniature cycle. It can be seen that the author sought to select semantic, verbal and syntactic forms in the direction of alignment, smoothing out inconsistencies, that is, in a neutral, generally significant and commonly used way. This observation led to the assumption that A. S. Ulyanov's miniatures can be used in language teaching and in inclusive education.

In a broader perspective, the genre of miniatures can be offered as an alternative to «clip thinking» - «through the Internet, you can effectively impose knowledge on the rest of the world, but you can also create effective alternative epistemological projects and models leading to altermodern possibilities» [19].

Miniaturization can be seen as a departure from «surfing» in information consumption to focusing on deep meanings concentrated in the deceptively small - the text of a prosaic miniature.

In the future, the work can be continued at the level of language analysis of A. S. Ulyanov's miniatures and the study of means of expressing the author's self-identification. It seems appropriate to consider the form-content and language gaps of the bilingual discrepancy between the Russian and Vepsian versions of the miniature cycle. It can be seen that the author sought to select semantic, verbal and syntactic forms in the direction of alignment, smoothing out inconsistencies, that is, in a neutral, generally significant and commonly used way. This observation led to the assumption that A. S. Ulyanov's miniatures can be used in language teaching and in inclusive education.

In a broader perspective, the genre of miniatures can be offered as an alternative to «clip thinking» - «through the Internet, you can effectively impose knowledge on the rest of the world, but you can also create effective alternative epistemological projects and models leading to altermodern possibilities» [19].

Miniaturization can be seen as a departure from «surfing» in information consumption to focusing on deep meanings concentrated in the deceptively small - the text of a prosaic miniature.

\section{References}

1. G.D. McConnell, V. Mikhalchenko, Written languages of the world. Languages of The Russian Federation 2, 97 - 113 (2003)

2. G.P. Ivanova, Preservation of the Language and Culture of a Small Ethnic Group (on the Example of the Veps), Nauchnyy dialog 3, 52-61 (2018) DOI: 10.24224/22271295-2018-3-52-61

3. Z.I. Strogalschikova, Veps in the ethno-cultural space of the European North. Karelian research center of the Russian Academy of Sciences, Institute of language, literature and history (2016)

4. R.B. Phillips, Trading Identities: The Souvenir in Native North American Art from the Northeast, 1700-1900 (University of Washington Press, 1998)

5. C. Knappett, Meaning in Miniature: Semiotic Networks in Material Culture. Excavating the Mind: Cross Sections through Culture, Cognition and Materiality, Aarhus, Aarhus University Press 87-109 (2012) 
6. J. Davy, C. Dixon, Worlds in Miniature: Contemplating Miniaturisation in Global Material Culture (London: UCL Press, 2019) DOI: https://doi.org/10.14324/111. 9781787356481

7. L.A. Levitsky, Miniature, Brief literary encyclopedia1962-1978, 4 (1967)

8. Yu.B. Orlitsky, Prose miniature in the work of N. M. Karamzin 3, 11-21 (2016) DOI: $10.5922 / 2225-5346$

9. N.L. Leiderman, The theory of the genre. Research and analysis (Ural state pedagogical Un-t, Yekaterinburg, 904, 2010)

10. I.P. Smirnov, Literaturnoe time: (Hypo)theory of literary genres, 262 (2008)

11. O.N. Astafieva, National and cultural identity in the context of globalization: a complex vector of development, Vestnik MGUKI 5 (73) (2016)

12. Philosophical encyclopedic dictionary (2010)

13. A.G. Dugin, Ethnosociology (Academic Project, Moscow, 634, 2011)

14. E. Fromm, «Have» or «be» Erich Fromm (Moscow, AST, 314, 2008)

15. A. Giddens, Modernity and selfidentity. Stanford (Calif.), Stanford univ. Press (1991)

16. R.L. Lachmann, Discourses of the fantastic, Moscow, New literary review 384 (2009)

17. W.J. Lin, A.J. Horner, N. Burgess, Ventromedial prefrontal cortex, adding value to autobiographical memories, Sci Rep. Published (2016) doi:10.1038/srep28630https://pubmed.ncbi.nlm.nih.gov/27338616/

18. E. Ivanov, G. Ivanova, Public Lectures on the Novel of G. Gazdanov an Evening with Claire (2018) doi: https: //dx.doi.org/10.15405/epsbs. 2018.12.02.191

19. M.V. Tlostanova, Space-time matrix of modernity in the context of globalization, Bulletin of the Moscow University, Publishing house 5, 48-63 (2010) 